\title{
NPP: Protecting the environment
}

\author{
Haryono Santosa ${ }^{1 *}$, Muhammad $\mathrm{Hadi}^{2}$, and Yudi Imardjoko ${ }^{3}$ \\ ${ }^{1}$ Universitas Gadjah Mada, The Graduate School, Jl. Teknika Utara, Yogyakarta, 55284, Indonesia \\ ${ }^{2}$ Universitas Gadjah Mada, Faculty of Geography, Sekip Utara, Bulaksumur, Yogyakarta 55281, Indonesia \\ ${ }^{3}$ Universitas Gadjah Mada, Nuclear Engineering and Engineering Physic Department, Jl. Grafika 2, Yogyakarta 55281, Indonesia
}

\begin{abstract}
Nuclear energy is a good option for the environment, but the potential for NPP to harm the environment is still evident. Safety is used by NPP to protect its environment. Low environmental risk was demonstrated, but the last two accidents resulted in disaster. Environmental protection parties need to participate in reducing environmental hazards of NPP by knowing why NPP is harmful and how to compensate. The perspective of protecting the environment is needed. An exploratory study of NPP's environmental protection was conducted to obtain answers. Publications from institutions engaged in NPP and expert opinions are sources of information. The results obtained indicate that there is optimism on the success of confining fission products, but very little control has been done on the quantity. No environmental protection is carried out when accidents occur, so environmental goods and services are sacrificed. Human protection is the focus. References to environmental radiological protection are still limited to animal and plant species and have not touched environmental goods and services. This allows for an imbalance between the potential radiological load of the NPP and the environmental capacity. It is necessary to develop the idea that NPP is not significantly dangerous in an accident.
\end{abstract}

\section{Introduction}

Nuclear energy is the type of energy that is needed today because it is low-carbon and conservative in natural resources. But this superior characteristic does not improve its contribution to the energy mix of Indonesia and the world. Many factors determine the acceptance of nuclear energy, one of which is the ability of a nuclear power plant (NPP) to protect the environment. The adverse environmental impacts caused by the accident of the Fukushima Daiichi NPP in Japan (2011) and the Chernobyl NPP in Ukraine (1986) [1, 2] are technological failure events that should not be forgotten so that it does not happen again [3]. The concept and technological implementation of NPPs in protecting the environment is important in this regard. Improvements are needed to make nuclear power plants capable to protect the environment in the future, so that the use of nuclear energy can increase.

The environmental perspective needs to take into account the environmental protection methodology applied to NPP technology. This makes environmental protection parties need to understand the methodology applied so far. Thinking about how NPP technology protects the environment is still lacking. This can be seen from the research articles produced between January 1955 to June 2021. The topics of nuclear power plants are 33,430 articles, nuclear power plants and accidents 9,151 articles, nuclear power plants and accidents and environmental protection (not waste) 1,224 articles, nuclear power plants and accidents and environmental protection and safety principles 79 articles, NPP and accidents and environmental protection and safety and emergency principles 23 articles [4]. The last topic relates to how nuclear power plants protect their environment in the event of an accident, but mostly relates to human protection and the relationship between NPPs and earthquake events.

An exploratory study of the publications of institutions engaged in nuclear power plants and expert opinion was carried out in order to understand NPP technology in protecting the environment. Environmental protection opinion is expected to be the result of this study.

\section{Nuclear power plant (NPP)}

NPP works like steam power plants. NPP fuel is nuclear fissile uranium $235\left({ }^{235} \mathrm{U}\right)$ which is called nuclear fuel, and fission is its combustion reaction. Some nuclear fuel containing ${ }^{235} \mathrm{U}$ is fed into the reactor vessel and forms the reactor core. Each ${ }^{235} \mathrm{U}$ fission reaction generates $200 \mathrm{MeV}$ of heat (3.2.10-1 1 watt-second per fission) [5], so to produce $1 \mathrm{MWe}$ of electricity, 9.3.10 fission/second is required $(33.3 \%$ thermal-electric efficiency). Nuclear fuel is designed to be able to provide a certain amount of heat energy called burn up. The values generally range from 7 to 50 gigawatt days per tonne of nuclear fuel $(\mathrm{GWd} / \mathrm{tHM})$. This makes nuclear fuel in the reactor for a long period of time $(\geq 1$ year) before being removed from the reactor as spent fuel [6]. This characteristic indicates the presence of a

\footnotetext{
* Corresponding author: hbsantosa@gmail.com
} 
very large excess of ${ }^{235} \mathrm{U}$ nuclei in the reactor at all times.

The heat balance between fission heat generation and extraction is formed in the nuclear power plant reactor. A heat removal system is provided to take the fission heat generated in the nuclear fuel. The heat taken is used to generate steam for turning the electric turbine. This system is also called a nuclear fuel cooling system because it will lower or maintain the temperature of the nuclear fuel. The heat balance is designed to be balanced because the imbalance can heat the nuclear fuel excessively [5].

The fission reaction of ${ }^{235} \mathrm{U}$ produces fission fragments in addition to generating fission heat. The fission fragments are unstable, therefore they decay to form other atomic nuclei by emitting beta and gamma radiation which ionize biological cells. The combination of fission fragment radionuclides and their decay products is called a fission product. The fission products are in nuclear fuel. The fission product radionuclides can be grouped into inert (noble gases: $\mathrm{Xe}, \mathrm{Kr}$ ), volatile (halogens, alkali metals, tellurium groups) and nonvolatile (alkali earths, noble metals, rare earths and refractory oxides) groups [5]. Another group that can be added is radionuclides that emit neutrons in their decay (neutron precursors) [7]. All nuclear fuel in the reactor forms a core, then all of its fission products form the radioactive activity of the reactor core or core inventory. The inventory value of large NPP cores (>500 MWe) can reach hundreds of $\mathrm{EBq}\left(10^{18} \mathrm{~Bq}\right)[5]$. The greater the NPP's power generation capacity, the greater the inventory.

All fission products are contained in nuclear fuel. This confinement is a standard function provided to restrain its movement. The existence of this function makes NPP have a basic function of operation and safety, namely controlling the generation of fission heat, taking heat (cooling biofuels) and confining fission products [8].

Commercial NPP uses certain types of nuclear reactors that can be distinguished from the energy of the neutrons to trigger fission reactions, moderators, heat removal (nuclear fuel coolant) and steam generation methods [9]. Fission reactions in nuclear power reactors can occur with thermal neutrons (low energy) or fast neutrons (high energy), so there are known thermal reactors and fast reactors. Thermal reactors require a moderator to lower the energy of the neutrons. The material used is $\mathrm{H}_{2} \mathrm{O}, \mathrm{D}_{2} \mathrm{O}$ or graphite. Heat can be taken up by water or gas $\left(\mathrm{CO}_{2}\right)$. Steam generation can take place inside the reactor by boiling, but it can take place in a steam generating device outside the reactor. The second method of taking heat requires that the heat removing fluid does not experience boiling, therefore high pressure is applied. The combination of these parameters produces different nuclear reactors for NPP. A summary of the types of commercial nuclear reactors is shown in Figure 1.

The description of NPP technology shows three important characteristics. The NPP has a ${ }^{235} \mathrm{U}$ nucleus which is larger than its instantaneous requirement. This excess is the potential for heat generation to be faster and larger than it should be (nuclear excursions).
Second, nuclear power plants have fission products with high radioactive activity. Third, NPP has a heat balance that must be maintained in balance in order to maintain the integrity of nuclear fuel as a containment for fission products. Nuclear power plants have the basic safety function of controlling fission heat generation, removing heat (cooling nuclear fuel) and confining fission products.

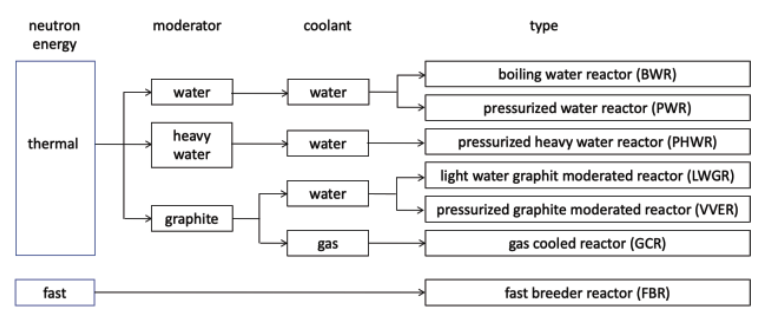

ER:Vodo-Vodyanol Energetichesky Reakior

Fig.1. Types of NPP reactors (modification of [9]).

\section{Hazards of NPP}

NPP technology was developed to obtain abundant clean energy [10], but it is accompanied by danger to life. Long before fission reactions were discovered, the dangers of ionizing radiation were known [11]. Furthermore, the experience of the atomic bomb explosion destroying life through the extremely fast fission reaction of ${ }^{235} \mathrm{U}$ and ${ }^{239} \mathrm{Pu}$, is seen as a danger from the use of nuclear energy. This view is evident in the statement Alvin Weinberg, a nuclear physicist, told the Special Committee on Atomic Energy, United States Congress in late 1945, "atomic power can heal and kill, can fertilize and enrich an area and destroy it, can broaden human horizons and forced him back into the cave [12]. The experience of operating a research power reactor has strengthened awareness of the dangers of NPP. In 1952 there was a nuclear excursion accident at the NRX research reactor in Canada. The excess of ${ }^{235} \mathrm{U}$ nucleus in the reactor underwent an improper fission reaction (nuclear excursion) due to failure to control the fission reaction. This failure resulted in a heat balance disturbance which increased the nuclear fuel temperature significantly. Excessive heat accumulation results in the melting of nuclear fuel and the release of fission products [13]. This incident raises awareness that accidents at nuclear reactors cannot be ruled out so that more confinement is needed than nuclear fuel alone. Strong and tight structure confining reactor vessel and cooling systems are recommended [8].

Two views on how to start NPP evolved during the development of the technology. The first view directly realizes the NPP with the belief that there is always a solution to the problems that arise. The second view chooses to solve problems first before realizing the NPP. This view found a solution to the problem of nuclear excursions. This settlement managed to tame the wildness of the nuclear reactor. [14]. The first view gave birth to the world's first NPP in 1954 in Obninsk, Russia. The second view gave birth to NPPs a little slower. The two views are united on the economic aspect. Both argue that the larger the capacity of a nuclear power plant, the 
lower the cost of production, so that it can compete with fossil energy prices [14].

Events that occurred in the pre-NPP period show that NPP is dangerous because it contains a large number of fission products whose radiation is harmful to humans, has the potential to damage nuclear fuel so that it releases fission products into the environment (accidents), and tends to prioritize energy production rather than limiting its fission product content.

\section{Safety of NPP}

The operation of a NPP is considered to be in an operational state or an accident based on the control, hazards and potential accidents. Operational conditions include normal operation and deviations. This deviation is calculated not to cause significant equipment damage to the safety equipment. Accident circumstances include design base accidents and design extension conditions. A design basis accident is a postulated event for which anticipation and compensation have been provided. The escape of fission products that occur is considered to be within acceptable limits. as the basis for the design of NPPs. Design extension conditions are postulated events that do not form the basis of the design and are still considered in the design process and the release of the fission product is kept within acceptable limits. This condition can be without significant nuclear fuel damage or with melting of the reactor core [15]. The summary of NPP status is shown in Figure 2.

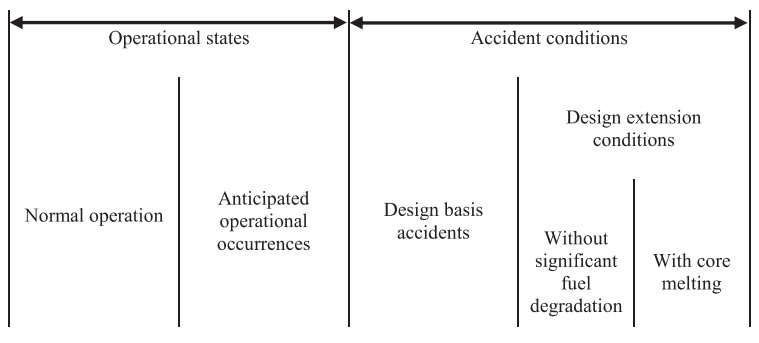

Fig. 2. States of NPP [15].

NPP technology was developed to anticipate the dangers and potential accidents. The existence of danger in the NPP gave birth to international safety standards. Its fundamental safety goal is "to protect people and the environment from the harmful effects of ionizing radiation." [16]. Fundamental safety objectives guide the attainment of the highest safety possible through the prevention of accidents with hazardous consequences caused by loss of control over the reactor core (heat of fission and decay), ensuring that the radiological consequences of all accidents are below the relevant limits that are reasonably achievable, and ensuring that the probability of an accident with serious radiological consequences is very low [17].

The main way to prevent accidents and reduce their consequences when they occur is developed through the principle of defense in depth. Five layers of defense that are independent of each other make up this principle. The first defense is aimed at preventing deviations from normal operation and the failure of items critical to safety. The second defense aims to detect and control deviations from normal operating conditions to prevent anticipated operational events at the plant from escalating into accidental conditions. The third defense aims to keep the state of development within the design base accident so that compensation is available. The fourth defense aims to reduce the consequences of accidents resulting from the failure of the third level of defense. The fifth level of defense aims to reduce the radiological consequences of potentially accidental radioactive releases. On-site and off-site emergency response plans, procedures and facilities are used for this purpose. This concept is applied to all activities related to safety at the design, organizational, supervisory and behavioral levels [17].

The implementation of the defense in depth principle is always assessed in a deterministic and probabilistic manner [8]. Deterministic assessment produces safety criteria as a result of causality. Probabilistic assessment is used to deal with the random nature of accidents with both internal and external causes. The principle of defense in depth is the standard approach to NPP safety [17]. This principle has grown and developed since 1956 [18]. A number of changes have occurred after the NPP accident $[8,18]$. The NPP safety framework is within the scope of international standards consisting of fundamental safety objectives and principles, general and specific requirements and safety guidelines [16].

\section{Protection and safety}

The protection of the public and the environment from the harmful effects of ionizing radiation is largely influenced by the safety characteristics and recommendations of the International Commission on Radiological Protection (ICRP).

\subsection{Public protection}

NPP hazard management to protect the public and the environment is carried out through the concept of "protection and safety". This concept is defined as "the protection of people against exposure to ionizing radiation or exposure due to radioactive materials and the safety of the source, including the means to achieve this, and the means to prevent accidents and to reduce the consequences of accidents if they occur" [15]. Protection is defined as protection of persons from exposure to ionizing radiation, whereas safety is defined as control of radiation sources (fission products) [15]. If protection and safety is seen as a way, then this method includes ways to achieve it, prevent accidents and reduce the consequences of accidents if they occur. The word accident in the description is defined as "any undesired event, including operating errors, equipment failure and other accidents, the consequences or potential consequences of which cannot be ignored from a protection and safety point of view" [15]. If the meaning of control is used, then protection (radiation) means controlling radiation exposure and its effects, while safety means maintaining control over the source (radiation). The word source in this case includes 
nuclear installations in addition to functions for other radioactive materials, where nuclear reactors are included in nuclear installations [15].

Safety is primarily concerned with maintaining control over radiation sources (fission products), whereas protection (radiation) is primarily concerned with controlling radiation exposure and its effects. Obviously the two are closely related: radiation protection (or radiological protection) is much simpler when the source in question is under control, so safety must contribute to protection [15].

\subsection{Environmental protection}

The environment is seen as an entity that does not include humans. Environment as "the conditions in which humans, animals and plants live or develop and which sustain all life and development; especially conditions such as those affected by human activities." [15]. Environmental protection has its own definition, namely "protection and conservation: non-human species, both animal and plant, and their biological diversity; environmental goods and services such as food and feed production; resources used in agriculture, forestry, fisheries and tourism; facilities used in spiritual, cultural and recreational activities; media such as soil, water and air; and natural processes such as the carbon, nitrogen and water cycles." [15].

Protection of the environment is now contained in the ICRP recommendations recently. The purpose of environmental protection is to prevent or reduce the frequency of harmful radiation effects on biota, species conservation; or the health and status of natural habitats, communities, and ecosystems. Environmental protection in the sense of preventing pollution of environmental media (soil, water, sediment, and air) which are environmental resources of value to humans or protecting nature has not yet become the center of attention. Environmental media is seen as a pathway for radiation exposure in humans and biota [19].

\section{NPP accident and environmental impact}

NPP's nearly seven decades of operation suffered three serious accidents that released fission products into the environment. The last accident occurred at NPP Fukushima Daiichi units 1 (460 MWe), 2 (784 MWe) and 3 (784 MWe) in 2011. The accident occurred when the three NPP units were turned off. The shutdown of nuclear reactors automatically takes place immediately after an earthquake on the east coast of Japan [1]. This accident resulted in radioactive contamination of the terrestrial, aquatic and oceanic environments. The total contaminated area reaches thousands of square kilometers, but for the oceans it is difficult to determine. No fatalities occurred, but the evacuation of large numbers of residents and the partial relocation of some did occur [20]. The collapse of environmental goods and services occurs in contaminated areas. This indicates the escape of radioactive fission products that occur exceeds the acceptable limit. Huge costs arise for the sake of population emergencies and environmental restoration, but it still leaves an area of land that cannot be re-used [21]. Natural events in the form of tsunami waves are designated as the cause of external accidents [1].

Questions about the ability of NPP technology to protect the environment emerged and intensified after the accident. The Japan Nuclear Safety Institute invites all parties to think deeply about safety practices in the form of compliance that have been implemented so far [22]. The NPP utility recognizes weaknesses in the applied safety culture, which weakens the application of the defense in depth principle [23]. The findings of the Fukushima NPP weaknesses and suggestions for improvement are all in the realm of layered defense [24, $25]$. Improvements to international safety standards and global safety regimes took place after the accident under the coordination of the IAEA [26].

More severe environmental impacts occurred after the NPP Chernobyl unit 4 in Ukraine had an accident in 1986. The accident occurred during a test run of the emergency power supply system [27, 28]. Fission products with $14 \mathrm{EBq}$ activity released to the environment of a number of countries. Land and air contamination of more than $200,000 \mathrm{~km}^{2}$ occurred. The evacuation of hundreds of thousands of residents in the contaminated area is underway. Some of them had to relocate their residences [29]. Environmental restoration is not easy to do because it requires a very large cost. The large land area is calculated not to be taken advantage of until hundreds of years into the future [30]. International assistance is needed to restore the environment [31]. The results of the investigation showed that there were weaknesses in all aspects related to safety, including the application of the principle of defense in depth [28].

The Chernobyl accident gave birth to a global nuclear safety regime. Previous safety practices were national. Each country that develops nuclear power technology uses their own safety standards [32].

The NPP accident that released radioactive fission products happened before Chernobyl. The accident occurred at Three Mile Island NPP unit 2 in the United States in 1979. The escape of fission products resulted in mild environmental radioactive contamination. Imperfections in nuclear power plant design and lack of operator knowledge were identified as the causes of accidents [33, 34]. Light environmental impact was assessed as the effectiveness of the layered defense principle [35].

All three NPP accidents show the release of radioactive fission products of more than acceptable activity limits can occur. The public and the environment are victims of these accidents [36]. The cause of the accident is evolving. Its development has involved unpredictable natural events. The application of the principle of defense in depth to deal with the causes of accidents that are not easily predictable reduces its effectiveness. The content of fission products in nuclear power plants is not a safety parameter. 


\section{Discussion}

Fission products are a hazard to NPP for the public and the environment. The greater the NPP power generation capacity, the greater the content of fission products. The high content of radioactive fission products as a public and environmental hazard tends not to be a controlled safety variable, even though the greater the activity, the greater the decay heat. The nuclear fuel damage in the Three Mile Island unit 2 and Fukushima Daiichi accidents was caused by the decay heat that radiates when cooling fails.

The release of fission products into the environment from nuclear power plants is determined by the effectiveness of their containment. The containment layer of fission products in the form of nuclear fuel, reactor vessel and cooling system, as well as the containment structure of the reactor vessel and cooling system was not effective enough in the Fukushima Daiichi nuclear power plant accident. The heat and high pressure generated when some of the nuclear fuel melts is able to penetrate the enclosure provided. This shows that the NPP has a self-destructive power that exceeds the provided compensation power.

Accident prevention through defenses 1, 2 and 3 is potentially ineffective when the trigger or cause of the accident is not well known. This can be seen in the Fukushima Daiichi accident. Insufficient compensation for tsunami waves provided. The TMI and Chernobyl accidents occurred due to internal causes, while the Fukushina Daiichi accidents were caused or triggered by external factors (natural events). How capable NPP managers are in recognizing internal and external factors that could lead to accidents is a never ending question.

NPP technology is designed, built and operated with the intention of protecting people and the environment through accident prevention, reducing the consequences of fission product released from accidents that occur, and reducing the radiological consequences of fission product escape in the environment. Two things can be seen from the protection procedures. Objects that are considered important to be protected are humans and non-human living objects (biota, animals, plants). Environmental media such as soil, water and air are not objects of protection, but are seen as a pathway for exposure to living things. Contamination that occurs in soil, water and air as a result of the Fukushima Daiichi and Chernobyl accidents can clearly disrupt people's lives and destroy environmental services in the long term. If viewed from the perspective of the path of radiation exposure to living things, its existence can last a very long time and become a long-term radiological latent hazard as well. An environmental protection focus that does not include the protection of environmental goods and services may mean allowing environmental violence to occur.

\section{Conclusion}

- NPP technology has recognized the radiological hazards to humans and non-human species as well as environmental goods and services.

- Efforts to protect hazard recipients have been carried out through accident prevention, mitigating the escape of fission products and mitigating the radiological consequences of escapes, but still requires the participation of external parties to do so.

- Nuclear power plant technology has the potential to be called a technology that commits environmental violence because it does not make efforts to save the environment from the collapse of the value of its goods and services for life.

- Efforts to protect by regulating the content of fission products or power generation capacity in such a way as to limit the release of fission products due to accidents need to be carried out. The idea of designing a nuclear power plant technology based on an acceptable fission product released needs to be ensured for its implementation.

\section{References}

1. IAEA, The Fukushima Daiichi Accident, Technical Volume 1: Description And Context Of The Accident, Wina, Austria (2015)

2. IAEA, Environmental Consequences of The Chernobyl Accident and Their Remediation: Twenty Years of Experience, Report of the Chernobyl Forum Expert Group 'Environment', Wina, Austria (2015)

3. G. Santayana, Reason in Common Sense, p. 284, volume 1 of The Life of Reason

4. http://ugm.summon.serialssolutions.com/

5. E. Lewis, Nuclear Power Reactor Safety (John Wiley and Sons, New York, 1977)

6. H. Feiveson, Z. Mian, M.V. Ramana and F. von Hippel (Eds.), Managing Spent Fuel from Nuclear Power Reactors: Experience and Lessons from Around the World, International Panel on Fissile Materials (2011)

7. M.C. Brady, Evaluation and Application of Delayed Neutron Precursor Data, Los Alamos, N.M.: Los Alamos National Lab (1989)

8. IAEA, The Safety of Nuclear Power, A report by the International Nuclear Safety Advisory Group, INSAG-5, Wina, Austria (1992)

9. B. Wealer, S. Bauer, N. Landry, H. Seiß, C.R. von Hirschhausen, Nuclear power reactors worldwide: Technology developments, diffusion patterns, and country-by-country analysis of implementation (1951-2017), DIW Data Documentation, No. 93, Berlin: Deutsches Institut für Wirtschaftsforschung (DIW), (2018)

10. N.L. Char and B.J. Csik, IAEA Bulletin: The IAEA at 30, 3/1987, 19-25 (1987)

11. The British Journal of Radiology 7, New Series, No. 83, November, (1934) 
12. J.S. Walker and T.R. Wellock, A Short History of Nuclear Regulation, 1946-2009, NUREG/BR-0175, Rev. 2, U.S. Nuclear Regulatory Commission (2010)

13. W.B. Lewis, The Accident to the NRX Reactor on December 12, 1952, Chalk River, Ontario:Atomic Energy of Canada Limited (1953)

14. A.H. Snell, Geneva Diary, August 8-20, 1955, American Scientist, Vol. 43, No. 4 (October 1955), pp. 505-520 Published by: Sigma Xi, The Scientific Research Honor Society, Stable URL: https://www.jstor.org/stable/27826696 Accessed: 12-06-2021 06:09 UTC

15. IAEA, IAEA Safety Glossary, Terminology Used in Nuclear Safety and Radiation Protection 2018 Edition, Wina, Austria (2019)

16. IAEA, Fundamental Safety Principles, Safety Fundamentals, IAEA Safety Standards Series No. SF-1, Wina, Austria (2006)

17. IAEA, Safety of Nuclear Power Plants: Design, Specific Safety Requirements, IAEA Safety Standards Series No. SSR-2/1 (Rev. 1)

18. M. Drouin, B.Wagner, J. Lehner, V.Mubayi, Historical Review and Observations of Defense-inDepth, NUREG/KM-0009, Washington D.C: U.S. Nuclear Regulatory Commission (2016)

19. ICRP, Protection of the environment under different exposure situations. ICRP Publication 124, Ann. ICRP 43(1) (2014).

20. IAEA, The Fukushima Daiichi Accident, Technical Volume 4: Radiological Consequences, Wina, Austria (2015).

21. IAEA, The Fukushima Daiichi Accident, Technical Volume 5: Post Accident Recovery, Wina, Austria (2015)

22. S. Matsuura, New Paradigm for Nuclear Safety, Japan Nuclear Safety Institute (2013)

23. The Development of and Lessons from the Fukushima Daiichi Nuclear Accident, 1st edition, Tokyo Electric Power Company, Inc (2013)

24. J. Buongiorno, R. Ballinger, M. Driscoll, B. Forget, C. Forsberg, M. Golay, M. Kazimi, N. Todreas, J. Yanch, Technical Lessons Learned from the Fukushima-Daichii Accident and Possible Corrective Actions for the Nuclear Industry: An Initial Evaluation, Cambridge, M.A.: Massachusetts Institute of Technology (2011)

25. A. Omoto, The accident at TEPCO's FukushimaDaiichi Nuclear Power Station: What went wrong and what lessons are universal? Nuclear Instruments and Methods in Physics Research A, 731, (2013) 37

26. Progress in the Implementation of the IAEA Action Plan on Nuclear Safety, Report by the Director General, GOV/INF/2015/13-GC(59)/INF/5 (31 July 2015)

27. Department of Energy; Electric Power Research Institute; Environmental Protection Agency; Federal Emergency Management Agency; Institute of Nuclear Power Operations; Nuclear Regulatory Commission, Report on the Accident at the Chernobyl Nuclear Power Station, Washington, D.C.: U.S. Nuclear Regulatory Commission (1987)
28. IAEA, The Chernobyl Accident: Updating of INSAG-1, INSAG-7, A report by the International Nuclear Safety Advisory Group, Wina, Austria (1992)

29. IAEA, Environmental Consequences of The Chernobyl Accident and Their Remediation: Twenty Years of Experience, Report of the Chernobyl Forum Expert Group 'Environment'. Wina, Austria (2006). ISBN 92-0-114705-8

30. V. Kashparov, Chernobyl: 30 Years of Radioactive Contamination Legacy, Ukrainian Institute of Agricultural Radiology (UIAR) of National University of Life and Environmental Sciences of Ukraine (NUBiP of Ukraine), Kiev, Ukraine (2016)

31. CHERNOBYL disaster: Why are the consequences still observed? and Why is the international assistance still critical? Belarus Foreign Ministry (April 2009), retrieved from www.mfa.gov.by

32. IAEA, Strengthening The Global Nuclear Safety Regime, INSAG-2, A report by the International Nuclear Safety Group, Wina, Austria (2006)

33. Three Mile Island Accident, Backgrounder, Office of Public Affair (2018), www.nrc.gov

34. 1979 Annual Report, Washington D.C.: U.S. Nuclear Regulatory Commissionn (1979)

35. L. Battist, J. Buchanan, F. Congel and H. Peterson,Population Dose And Health Impactof The Accident at The Three Mile Island Nuclear Station, Preliminary Estimates Prepared by Ad Hoc Interagency Dose Assessment Group, NUREG0558, Washington, D.C.: U.S. Nuclear Regulatory Commission (1979)

36. E. Molodstova, Pace Envtl. L. Rev. 185 (1994) 